\title{
Psychological Aspects of Shopping Addiction: Initial Test of a Stress and Coping Model
}

\author{
Tony Cassidy*, Zara Adair \\ School of Psychology, Ulster University, Coleraine, Northern Ireland
}

Email address:

t.cassidy@ulster.ac.uk (T. Cassidy)

${ }^{*}$ Corresponding author

\section{To cite this article:}

Tony Cassidy, Zara Adair. Psychological Aspects of Shopping Addiction: Initial Test of a Stress and Coping Model. International Journal of Psychological and Brain Sciences. Vol. 6, No. 2, 2021, pp. 29-35. doi: 10.11648/j.ijpbs.20210602.12

Received: May 11, 2021; Accepted: May 24, 2021; Published: June 3, 2021

\begin{abstract}
There is evidence to suggest that compulsive buying has all the elements of addictive behaviour and can become a psychological problem requiring intervention. The behaviour itself can be triggered by difficulties and distress and generate positive benefits for wellbeing in the short term. Longer term effects can be guilt, anxiety, and depression this sparking a negative affectivity cycle. Interest in the area has been reignited by the growth in online shopping during the recent COVID-19 Pandemic. This study aimed to explore a stress process model of shopping addiction by assessing the relationship between perceived stress, relationship satisfaction, rejection sensitivity, resilience, self-efficacy, loneliness, healthy lifestyle and wellbeing in female emerging adults. The study was based on an online survey of 332 females aged between 18-26 years and used questionnaire data collection. Data were analysed using correlations and path analysis with AMOS 26 software. Results show strong direct relationships between loneliness, rejection sensitivity and shopping addiction, with inverse relationships with resilience, self-efficacy, and relationship satisfaction. There is a reciprocal relationship between wellbeing and shopping addiction, which appears to be a symptom of underlying emotional difficulties. As a widespread and ultimately damaging behaviour it is suggested that it should be taken more seriously than is currently the case.
\end{abstract}

Keywords: Shopping Addiction, Relationship Satisfaction, Loneliness, Rejection Sensitivity, Wellbeing

\section{Introduction}

Excessive and compulsive shopping have been recognised as symptoms of addictive behaviour for over one hundred years [1]. Evidence shows that compulsive buying contains the main behavioural elements associated with other addictions [2]. Compulsive or mindless buying has been shown to reduce negative mood and is used as a coping method in which context it has also been referred to as retail therapy [3]. There is some evidence that females are more prone to compulsive buying [4].

There have been several studies exploring the neurological correlates of compulsive buying. One involved a neurological assessment of compulsive buyers and concluded there were no neurological deficits but did show that compulsive buyers were more prone to lifetime depression, mood and anxiety disorders, impulsivity, and some symptoms of ADHD [5]. Another study found that compulsive buyers were more sensitive to cues for reward and were more reactive to cues related to items [6]. There is a consistent link between compulsive buying and failures to self-control and regulate behaviour [7].

One study draws on materialism as an explanation suggesting that compulsive buying is driven by materialistic concerns [8]. There are four potential explanations for materialist's engaging in compulsive buying cited in the literature. One relates to suggested conflict between selfcentred and more collectivist values leading to more negative affect [9]. Another suggests that the motivation to buy is centred on establishing a sense of identity through symbolic consumption [10]. Thirdly there is a suggestion that materialists hold unrealistic expectations and buying compensates for disappointment [11]. Finally, there is the suggestion that materialism leads to loneliness and buying compensates [12].

Escape Theory postulates that when people deviate from their own self-perception, that self-awareness becomes difficult to face and people are motivated to escape; one form 
of escape is in compulsive buying [8, 13]. Most of the research identifies loneliness as a factor in shopping addiction and as a negative self-perception it would be a candidate for escape [14]. These authors show that rejection sensitivity, defined as a tendency to expect and overreact to social rejection [15], is related to self-directed negative cognitions. Rejection sensitivity is a key factor in loneliness [16, 17], and is related to social isolation, difficult relationships, and negative affect [18]. It has also been shown to be related to internet addiction [19].

One study found a strong correlation between compulsive buying and compulsive hoarding though the study did not explicate the causes or consequences of either [20]. Others developed a theoretical framework to explain compulsive buying in terms of antecedents, response, and consequences [21]. They suggest a long list of antecedents including, compulsivity, low self-esteem, negative affect, loneliness, arousal seeking, fantasizing, credit usage, materialism, affect intensity, and impulsivity [21, p. 111]. These are a list of factors that have been identified from research and there is likely to be overlap. They list responses as non-low normative evaluations and impulse control. Consequences are split into short-term (emotional lift, isolation, increased self-esteem, debt and guilt), and long-term (depression, low self-esteem, debt, relationship problems, guilt, and legal issues). It is likely in reality that this is not a linear but rather a cyclical model where consequences become antecedents in an ongoing cycle of compulsion.

There is insufficient evidence to develop an a priori model but from the factors identified in the above review one might deduce a stress-process model in terms of antecedents, response, behaviour and consequences (see Figures 1 and 2). Based on stress research any event (or events) which trigger an imbalance to homeostasis in the hypothalamus, instigates the stress process in the hypothalamic-pituitary-adrenal-axis (HPA-axis) [22]. These events can be anything that is perceived as a threat by the person ranging from a major life event to boredom [23]. The immediate response is in terms of fight / flight emotions and attempts to regulate those emotions [24]. Compulsive shopping is one behaviour that can help to regulate these emotions by reducing emotional arousal (the consequence) in the short term. Reduced emotional arousal can be experienced in terms of elevated mood, increased sense of self-esteem, and sense of established self-efficacy [21]. These positive emotions can mask the underlying guilt, anxiety and depressed affect in the short term but as reality kicks in and negative emotions grow, these feedback into the stress appraisal process and the cycles is rejuvenated [21].

Empirical research on compulsive buying fell out of fashion a decade or more ago but in the context of the Coronavirus pandemic in 2019-20 it has increased relevance (The Pandemic and shopping addiction - The Hippocratic Post).

The aim of the current study is to explore the models in Figures 1 and 2 by assessing perceived stress, relationship satisfaction, rejection sensitivity, resilience, self-efficacy, loneliness, good health practices, wellbeing, and shopping addiction.

\section{Methods}

Design: Data was collected using questionnaire measures in an online survey to explore shopping addiction, perceived stress, good health practices, wellbeing, attachment, selfefficacy, resilience, and loneliness.

Participants: The sample consisted of 332 female emerging adults ranging in age from 18 to 26 years $(M=21.26, S D$ $=1.89$ ). Of these 231 were in a relationship and 101 were not.

Measures: Participants were asked for their age and relationship status before completing the following measures.

Shopping Addiction: This was measured using the Bergen Shopping Addiction Scale [1], which is a 7-item scale which has an internal consistency score of $\alpha=.87$.

Resilience is assessed using the Brief Resilience Scale (BRS) [25]. The BRS contains six items and scores range from 1 = Strongly Disagree to $5=$ Strongly Agree. The mean of the added scores were then used to indicate resilience, the higher the summation score, the higher the level of resilience. The Cronbach's alpha for the current study was 0.69 .

Self-Efficacy was measured using the General SelfEfficacy scale (GSE) [26]. The summed scores yielded a selfefficacy score, with higher scores denoting higher levels of perceived self-efficacy. Cronbach's alpha in this study was 0.76 .

Rejection Sensitivity Questionnaire [15]: The rejection sensitivity questionnaire assesses "generalized expectations and anxiety about whether significant others will meet one's needs for acceptance or will be rejecting" [15, p. 1329]. The 18-item scale presents hypothetical requests of people close to an individual (e.g "You ask your boyfriend/girlfriend if they really love you", "You ask your parents for extra money to cover living expenses"). Participants are required to state how anxious they would feel about making the request and how they think the person will respond to the request on a six-point likert scale. When answering the first part of each question, 1 represents "Very Unconcerned" and 6 represents "Very Concerned" on the likert scale. For the second part of each question 1 represents "Very Unlikely" and 6 represents "Very Likely". It is scored by reversing the likelihood estimates for all items, summing these products and dividing the total by 18 . Internal reliability was satisfactory with a Cronbachs alpha value of 0.92 . The authors reported a mean (std. deviation) of 9.69 (3.07), an internal consistency reliability of 0.81 and test-retest reliability of 0.83 .

Loneliness: This was measured by a short 3-item scale [27] for use in surveys. It was developed from the R-UCLA Loneliness Scale [28]. The scale had an Alpha of .72.

Perceived Stress. Perceived stress was measured using the Perceived Stress Scale (PSS); [29]. The PSS-4 is a 4-item self-report instrument revised from the 14-item measure of global perceived stress. PSS measures the degree to which, over the past month, the respondent has considered situations as stressful, particularly the perceived unpredictability and uncontrollability of such situations (e.g. how often have you felt that you were unable to control important things in your life?) All items were assessed using a 5-point Likert scale of 
agreement ranging from $0=$ Never, $1=$ Almost Never, 2=Sometimes, $3=$ Mostly True, 4=Always True. Cohen, et al. (1983) reported a coefficient alpha reliability of .72 for the 4item scale

Psychological wellbeing: The Warwick Edinburgh Mental Well-being Scale-short form [30] which is made up of seven positively worded items that relate to the different aspects of positive mental health. Each item was rated based on the experience of the respondent over the past two weeks, with items being ranked on a 5-point Likert scale ranging from $1=$ None of the Time to $5=$ All of the Time. The summed item scores were used to determine the level of positive mental well-being, with a higher score indicative of a higher level of positive mental well-being. The Cronbach's alpha for the scale in this study is 0.93 .

The Relationship Assessment Scale (RAS) [31] is a 7-item scale that was created to measure overall satisfaction in a relationship. It is appropriate for the assessment of dating or cohabitating couples as well as for married couples. Its items measure an individual's satisfaction within a specific relationship. Lower scores reflect low relationship satisfaction while higher scores are indicative of more satisfaction within the relationship. The RAS has been shown to have solid criterion-based validity as well as good testretest reliability [30]. In the current study, the Cronbach alpha for the Relationship Assessment Scale was .930.

The Good Health Practices Scale (GHPS); The GHPS is a 16-item questionnaire which aims to measure how much the

participant agrees with engaging with health behaviours. It uses a 5-point Likert scale measuring how strongly they agree or disagree with the health statements. The scale has been shown to have good internal reliability and applicable for both genders [32]. The Cronbach Alpha in this data was .80 .

Procedure: Following ethical approval from the university ethics committee and link to the survey was e-mailed to 600 female students from which 332 completed and usable surveys were returned.

Compliance with Ethical Standards

Conflicts of interest/Competing interests: Neither author has any conflict of interest.

All participants gave informed consent.

\section{Results}

Based on the model shown in Figures 1 and 2 the aim of this research was to explore the relationship between stress, relationship satisfaction, rejection sensitivity, resilience, selfefficacy, loneliness, shopping addiction, and both good health practices and wellbeing. The first stage in analysis involved exploring bivariate relations between the variables using Pearson Product Moment Correlations as shown in Table 1. There are a series of correlations between shopping addiction, wellbeing and good health practices with other variables that indicate some support for the model.

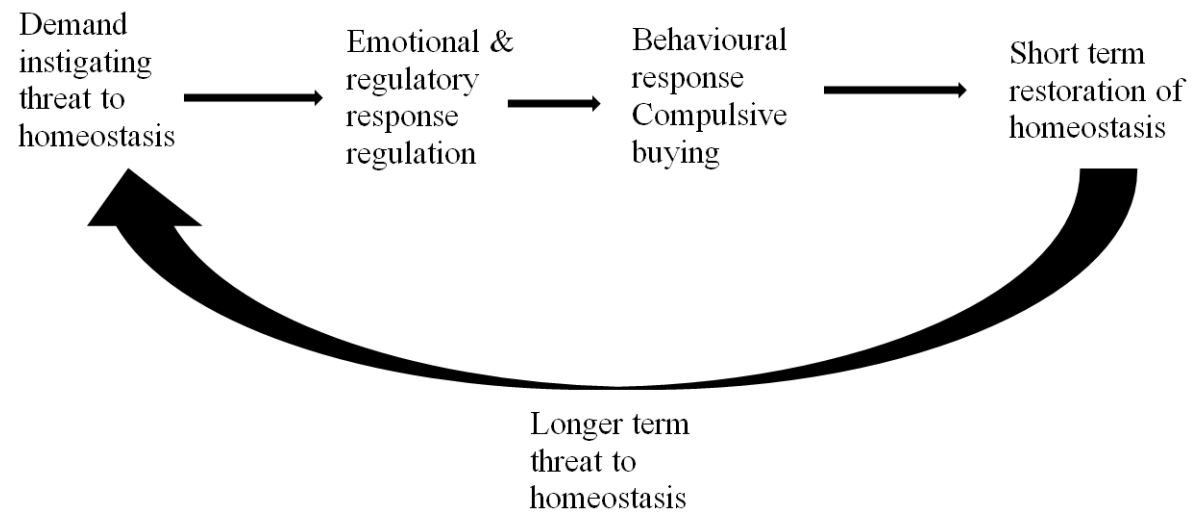

Figure 1. Theoretical model of compulsive buying.

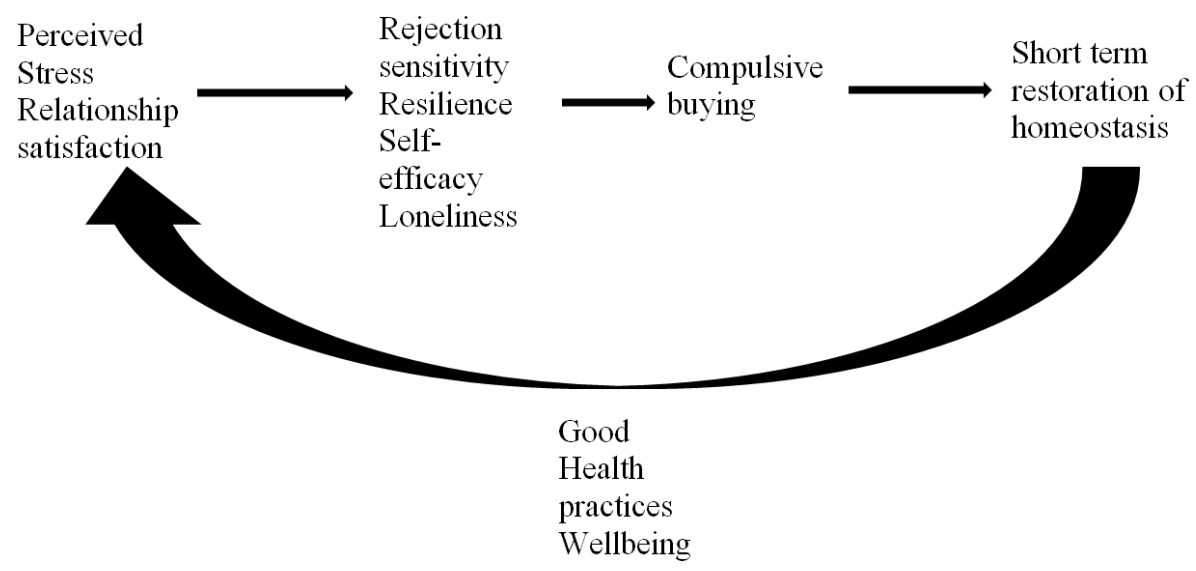

Figure 2. Theoretical model of selected variables compulsive buying. 
Table 1. Pearson bivariate correlations.

\begin{tabular}{|c|c|c|c|c|c|c|c|c|c|}
\hline & 1 & 3 & 4 & 5 & 6 & 7 & 8 & 9 & 10 \\
\hline \multicolumn{10}{|l|}{ 1. Age } \\
\hline 2. Relationship satisfaction & $-.12^{*}$ & & & & & & & & \\
\hline 3. Self-efficacy & .09 & $-.38^{* *}$ & & & & & & & \\
\hline 4. Resilience & -.02 & $-.35^{* *}$ & $.51^{* *}$ & & & & & & \\
\hline 5. Rejection sensitivity & -.03 & $.33^{* *}$ & $-.54^{* *}$ & $-.62^{* *}$ & & & & & \\
\hline 6. Loneliness & .09 & $.24^{* *}$ & $-.54^{* *}$ & $-.64^{* *}$ & $.62^{* *}$ & & & & \\
\hline 7. Shopping addiction & -.01 & $.39^{* *}$ & $-.74^{* *}$ & $-.72^{* *}$ & $.69^{* *}$ & $.71^{* *}$ & & & \\
\hline 8. Perceived stress & -.07 & $.42^{* *}$ & $-.76^{* *}$ & $-.59^{* *}$ & $.63^{* *}$ & $.66^{* *}$ & $.71^{* *}$ & & \\
\hline 9. Good health practices & .09 & $-.18^{* *}$ & $.57^{* *}$ & $.52^{* *}$ & $-.48^{* *}$ & $-.52^{* *}$ & $-.64^{* *}$ & $-.66^{* *}$ & \\
\hline 10. Wellbeing & -.05 & $-.26^{* *}$ & $.59^{* *}$ & $.59^{* *}$ & $-.60^{* *}$ & $-.68^{* *}$ & $-.73^{* *}$ & $-.65^{* *}$ & $.53^{* *}$ \\
\hline
\end{tabular}

${ }^{* *} \mathrm{p}<.01{ }^{*} \mathrm{p}<.05$

To test the model more robustly AMOS 26 software was used to examine the fit of variables in the model. The first model (Figure 3 ) looked at a path model of wellbeing. The model in Figure 3 was a good fit for the data $\left(\chi^{2}(12)=32.71\right.$, $\mathrm{Cmin} / \mathrm{df}=2.73$, NFI $=.98, \mathrm{IFI}=.99, \mathrm{CFI}=.99$, RMSEA $=.07$ ). The model supports a negative link between shopping addiction and wellbeing. Stress doesn't link directly to shopping addiction, but it has an indirect link via rejection sensitivity, loneliness, resilience and self-efficacy. Relationship satisfaction has a negative link with shopping addiction.

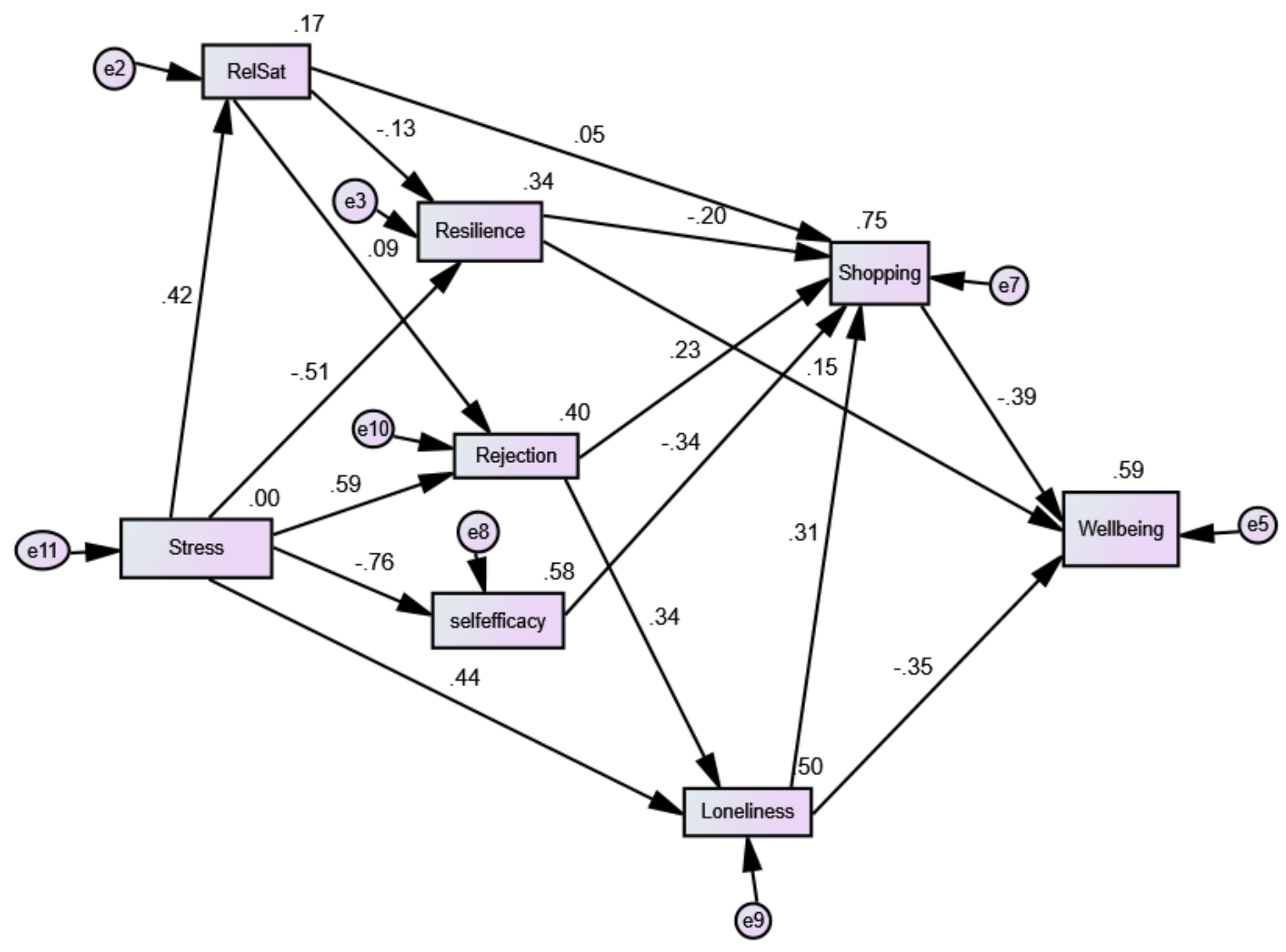

Figure 3. Path Model of the Predictors of Wellbeing.

We also tested a path model for good health practices as shown in Figure 4. The model was a good fit for the data $\left(\chi^{2}\right.$ $(10)=14.88, \mathrm{Cmin} / \mathrm{df}=1.49, \mathrm{NFI}=.99, \mathrm{IFI}=.99, \mathrm{CFI}$ $=.99$, RMSEA $=.04$ ). Again shopping addiction has a negative relationship with good health practices. Stress doesn't have a direct relationship but seems to be mediated through rejection sensitivity, loneliness, resilience and selfefficacy. 


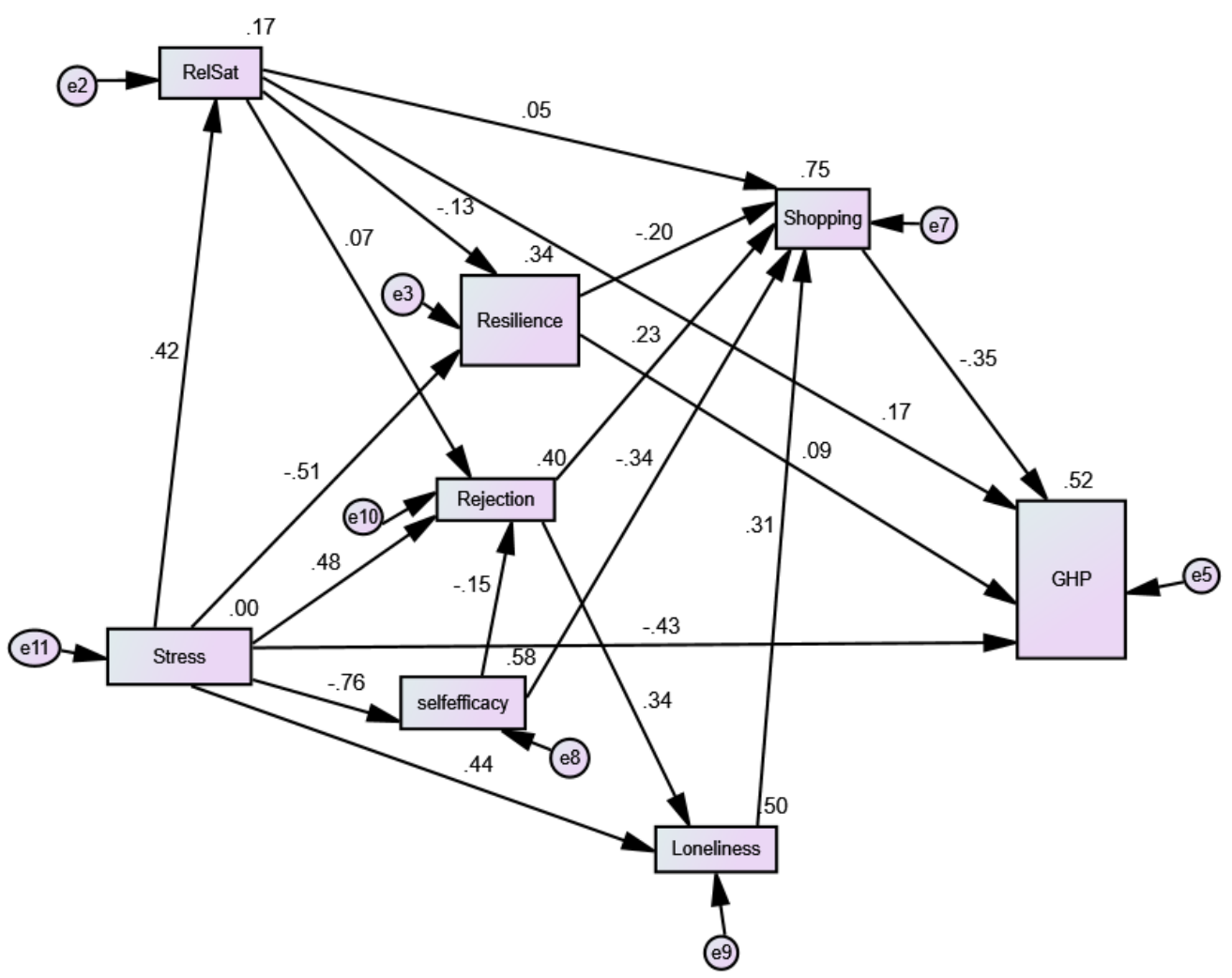

Figure 4. Path Model of the Predictors of Good Health Practice.

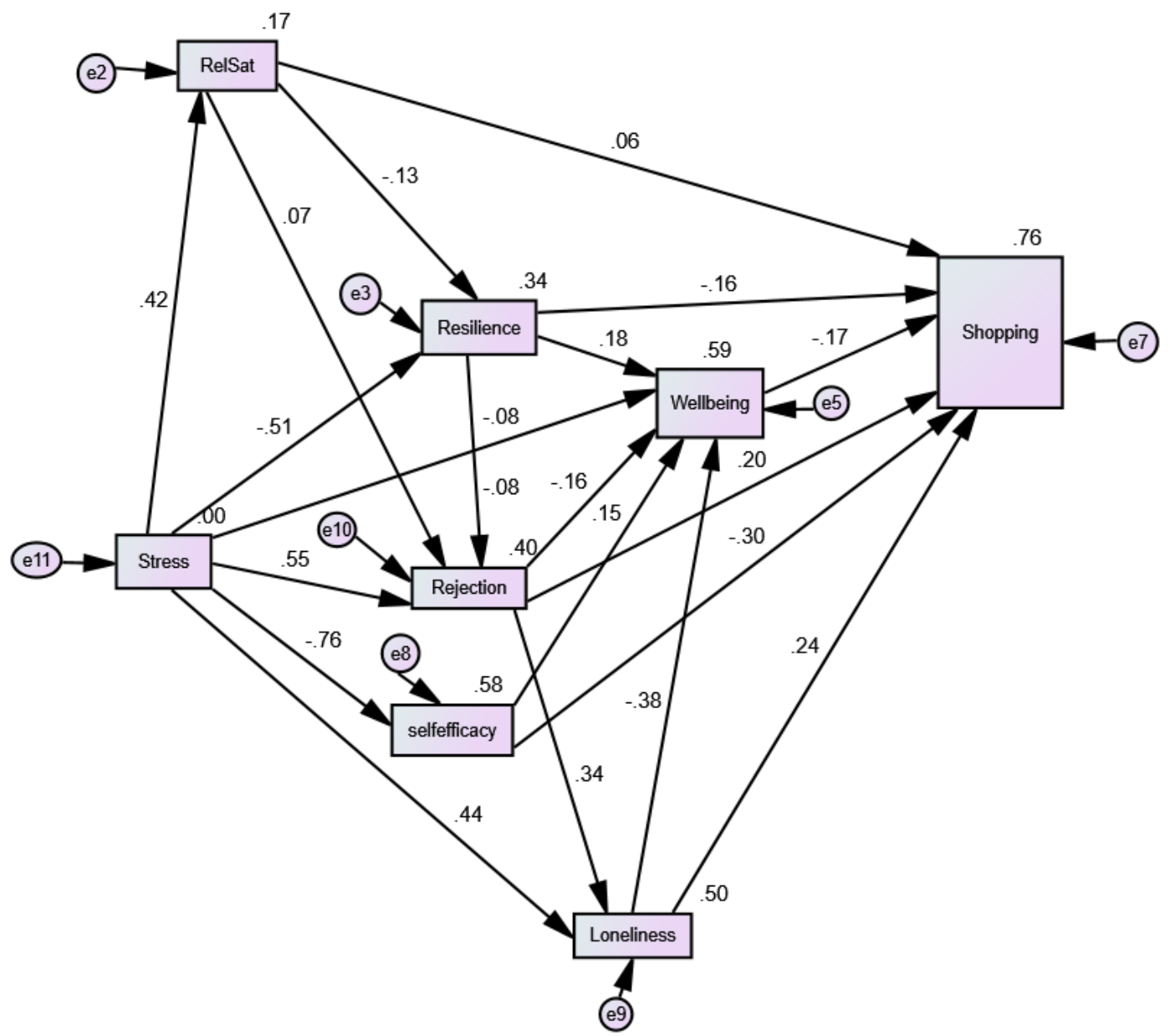

Figure 5. Path Model of the Predictors of Shopping Addiction. 
The final path model tested looked at the predictive relationships with shopping addiction (Figure 5). This model was again a good fit for the data $\left(\chi^{2}(7)=15.40, \mathrm{Cmin} / \mathrm{df}=\right.$ 2.20 , NFI $=.99$, IFI $=.99$, CFI $=.99$, RMSEA $=.06$ ). Loneliness and rejection sensitivity have a positive relationship with shopping addiction. Stress doesn't have a direct relationship but is indirectly related through rejection sensitivity, loneliness, resilience and self-efficacy. Resilience and self-efficacy have a direct inverse relationship with shopping addiction.

\section{Discussion}

The aim of this study was to explore the model set out in Figure $1 \mathrm{~b}$ through assessing the relationship between perceived stress, relationship satisfaction, rejection sensitivity, resilience, self-efficacy, loneliness, compulsive shopping (shopping addiction), good health practices and wellbeing. Bivariate correlation analysis suggests that the data may potentially support the model. From the path analysis there is further and stronger support for the model. The model for wellbeing shows a strong negative relationship between shopping addiction, loneliness and wellbeing suggesting that compulsive shoppers are more likely to be lonely and have lower wellbeing. The link between loneliness and wellbeing supports previous evidence $[16,12]$. From the same model more resilient individuals have better wellbeing. Those who are lonely and sensitive to rejection are more likely to be addicted to shopping, while those who are resilient, self-efficacious, and more satisfied with their relationships are less likely to engage in compulsive shopping. Stress seems to be to be related to an increase in sensitivity to rejection and loneliness, and to a reduction in resilience and self-efficacy. These variables seem to mediate the impact of stress on both shopping addiction and wellbeing.

The path model for good health practices suggests that stress and shopping addiction have a strong negative relationship so both related to less healthy lifestyles. Resilience and relationship satisfaction relate to more healthy lifestyles. Again, those who are lonely and sensitive to rejection are more likely to be addicted to shopping, while those who are resilient, self-efficacious, and more satisfied with their relationships are less likely to engage in compulsive shopping. Stress seems to be to be related to an increase in sensitivity to rejection and loneliness, and to a reduction in resilience and self-efficacy. These variables seem to mediate the impact of stress on both shopping addiction and wellbeing.

The final path model looks at shopping addiction as the final outcome. This model shows that rejection sensitivity and loneliness are related to increased shopping addiction while resilience and self-efficacy are related to reductions in the same variable. This time wellbeing is also a factor and suggests that those with better wellbeing are less likely to become shopping addicts. This potentially suggests that the relationship between wellbeing and shopping addiction is reciprocal and would support the feedback loop in the model.

The data is cross-sectional and precludes any causal claims, but it does suggest that the model provided in Figures 1 and 2 has some utility. Elements of the model are supported by previous research in that loneliness is a factor in shopping addiction [16, 12], as is sensitivity to social rejection [18]. Rejection sensitivity has been shown to be related to problematic relationships [18] and has been related to other forms of addiction [33].

\section{Conclusions}

Shopping addiction may not be a clinical disorder and it may not be useful to label it as such, but it does exhibit many of the behaviours associated with addiction and does cause distress [1-3]. It has become a widespread phenomenon and in practical terms it can lead to financial hardship and relationship break up [34]. As such there is a need to understand it and the current evidence would suggest that it is a symptom of underlying problems, a behavioural coping mechanism. In contexts such as the Corona Virus Pandemic, where other behavioural coping options may be restricted, and where compulsive buying is facilitated by online shopping availability, it can have a devastating effect on families.

\section{References}

[1] Andreassen, C. S., Griffiths, M. D., Pallesen, S., Bilder, R. M., Torsheim, T. \& Aboujaoude, E. (2015). The Bergen Shopping Addiction Scale: reliability and validity of a brief screening test. Frontiers in Psychology, 6: 1374 . doi: 10.3389/fpsyg.2015.01374.

[2] Clark, M. \& Calleja, K. (2008) Shopping addiction: A preliminary investigation among Maltese university students, Addiction Research \& Theory, 16: 6, 633-649, DOI: $10.1080 / 16066350801890050$.

[3] Atalay, A. S., \& Meloy, M. G. (2011). Retail Therapy: A Strategic Effort to Improve Mood Psychology \& Marketing, 28 (6): 638-660; DOI: 10.1002/mar.20404.

[4] Elliott, A. (2006). A girl's guide to retail therapy. New York: Barnes and Noble Publishing.

[5] Black, D. W., Shaw, M., McCormick, B., Bayless, J. D., \& Allen, J. (2012) Neuropsychological performance, impulsivity, ADHD symptoms, and novelty seeking in compulsive buying disorder. Psychiatry Research. 200 (2): 581-587.

[6] Lawrence, L. M., Ciorciari, J., \& Kyrios, M. (2014). Cognitive processes associated with compulsive buying behaviours and related EEG coherence. Psychiatry Research in Neuroimaging; 221 (1): 97-103.

[7] Faber, R. J., \& Vohs, K. (2004). To buy or not to buy? Selfcontrol and self-regulatory failure in purchase behavior. In R. F. Baumeister \& K. D. Vohs (Eds.), Handbook of selfregulation: Research, theory and applications (pp. 509-524). New York: Guilford Press. 
[8] Donnelly, G. E., Ksendzova, M., Howell, R. T., Vohs, K. D., \& Baumeister, R. F. (2016). Buying to Blunt Negative Feelings: Materialistic Escape from the Self. Review of General Psychology, $20 \quad$ (3), 272-316. https://doi.org/10.1037/gpr0000078

[9] Burroughs, J. E., \& Rindfleisch, A. (2002). Materialism and well-being: A conflicting values perspective. The Journal of Consumer Research, 29, 348-370. http://dx.doi.org/10.1086/344429

[10] Shrum, L. J., Wong, N., Arif, F., Chugani, S. K., Gunz, A., Lowrey, T. M., \& Sundie, J. (2013). Reconceptualizing materialism as identity goal pursuits: Functions, processes, and consequences. Journal of Business Research, 66, 11791185. http://dx.doi.org/10.1016/j.jbusres.2012.08.010

[11] Sirgy, M. J., Gurel-Atay, E., Webb, D., Cicic, M., Husic, M., Ekici, A.,... Johar, J. S. (2013). Is materialism all that bad? Effects on satisfaction with material life, life satisfaction, and economic motivation. Social Indicators Research, 110, 349366. http://dx.doi.org/10.1007/s11205-011-9934-2

[12] Pieters, R. (2013). Bidirectional dynamics of materialism and loneliness: Not just a vicious cycle. The Journal of Consumer Research, 40, 615-631. http://dx.doi.org/10.1086/671564

[13] Baumeister, R. F. (1988). Masochism as escape from self. Journal of Sex Research, 25, 28-59. http://dx.doi.org/10.1080/00224498809551444

[14] Breines, J. G., \& Ayduk, O. (2015). Rejection Sensitivity and Vulnerability to Self-Directed Hostile Cognitions Following Rejection. Journal of Personality 83: 1, DOI: 10.1111/jopy.12077.

[15] Downey, G., \& Feldman, S. I. (1996). Implications of rejection sensitivity for intimate relationships. Journal of Personality and Social Psychology, 70, 1327-1343.

[16] Ayduk, O., Mendoza-Denton, R., Mischel, W., Downey, G., Peake, P. K., \& Rodriguez, M. (2000). Regulating the interpersonal self: Strategic self-regulation for coping with rejection sensitivity. Journal of Personality and Social Psychology, 79 (5), 776-792. https://doi.org/10.1037/00223514.79.5.776

[17] Watson, J. \& Drew, N. (2012). Rejection Sensitivity, Social Withdrawal, and Loneliness in Young Adults. Journal of Applied Social Psychology, 42, 8, pp. 1984-2005. doi: 10.1111/j.1559-1816.2012.00927.x.

[18] Schaan, V. K., Schulz, A., Bernstein, M., Schachinger, H., \& Vogele, C. (2020) Effects of rejection intensity and rejection sensitivity on social approach behavior in women. PLOS ONE 15 (1): $\quad 0227799$. https://doi.org/10.1371/journal.pone.0227799

[19] Fontana, A., Callea, A., Casini, E. \& Curti, V. (2018). Rejection Sensitivity and internet addiction in adolescence: exploring the mediating role of emerging personality disorders. Clinical Neuropsychiatry. 15. 206.

[20] Mueller A, Mueller U, Albert P, Glaesmer, H., \& de Zwaan, M. (2007). Hoarding in a compulsive buying sample. Journal of Behaviour Therapy and Experimental Psychiatry; 45 (11): 2754-63.
[21] Workman, L., \& Paper, D. (2010). Compulsive Buying: A Theoretical Framework. The Journal of Business Inquiry, 9, 89-126.

[22] O'Connor, D. B., Thayer, J. F. \& Vedhara, K. (2021). Stress and Health: A Review of Psychobiological Processes. Annual Review of Psychology, 72, 663-688. Doi: 10.1146/annurevpsych-062520-122331.

[23] Folkman, S. (2012). Stress, Health, and Coping: Synthesis, Commentary, and Future Directions. In Susan Folkman (ed.) The Oxford Handbook of Stress, Health, and Coping. New York. Oxford University Press. DOI: 10.1093/oxfordhb/9780195375343.013.0022.

[24] Wang, M. \& Saudino, K. (2011). Emotion Regulation and Stress. Journal of Adult Development. 18. 95-103. 10.1007/s10804-010-9114-7.

[25] Smith, B. W., Dalen, J., Wiggins, K., Tooley, E., Christopher, P., \& Bernard, J. (2008). The Brief Resilience Scale. Measuring the Ability to Bounce Back. International Journal of Behavioral Medicine, 15: 194-200.

[26] Schwarzer, R. \& Jerusalem, M. (1995). Generalized SelfEfficacy Scale. In J. Weinman, S. Wright \& M. Johnston (Eds.), Measures in health psychology: A user's portfolio. Causal and control beliefs (35-37). Windsor, UK: NFERNELSON.

[27] Hughes, M. E., Waite, L. J., Hawkley, L. C. \& Cacioppo, J. T. (2004). A Short Scale for Measuring Loneliness in Large Surveys: Results from two Population-Based Studies. Research on Aging, 26 (6), 655-672. DOI: $10.1177 / 0164027504268574$.

[28] Russell, Dan, Peplau, L. A. \& Cutrona, C. E. 1980. The Revised UCLA Loneliness Scale: Concurrent and Discriminant Validity Evidence. Journal of Personality and Social Psychology 39: 472-80.

[29] Cohen, S., Kamarck, T., \& Mermelstein, R. (1983). A global measure of perceived stress. Journal of Health and Social Behavior, 24, 385-396.

[30] Tennant, R., Hiller, L., Fishwick, R., et al. (2007). The Warwick-Edinburgh Mental Well-being Scale (WEMWBS): Development and UK validation. Health and Quality of Life Outcomes, 5 (63), 1-13.

[31] Vaughn, M. \& Matyastik Baier, M. E. (1999). Reliability and validity of the Relationship Assessment Scale. American Journal of Family Therapy, 27 (2), 137-147.

[32] Hampson, S. E., Edmonds, G. W., \& Goldberg, L. R. (2019). The Health Behavior Checklist: Factor structure in community samples and validity of a revised good health practices scale. Journal of Health Psychology, 24 (8), 1103-1109. https://doi.org/10.1177/1359105316687629

[33] Leach, D., \& Kranzler, H. R. (2013). An Interpersonal Model of Addiction Relapse. Addictive Disorders \& their Treatment; 12 (4): 183-192. DOI: 10.1097/adt.0b013e31826ac408.

[34] Koran, L. M., Faber R. J., Aboujaoude, E., Large, M. D., \& Serpe, R. T., (2006). Estimated Prevalence of Compulsive Buying Behavior in the United States. American Journal of Psychiatry 163: 10, 1806-1812. 